\title{
Re-Designing the Library for Design Engineering
}

\author{
Sharon Murphy \\ Head, Engineering \& Science Library \\ Queen's University \\ murphys@queensu.ca
}

\author{
Nasser Saleh \\ Nasser Saleh \\ Integrated Learning Librarian \\ Queen's University \\ nasser.saleh@queensu.ca
}

\begin{abstract}
This paper relates our experience at the Engineering \& Science Library at Queen's University, melding Library resources into the design engineering curriculum in the Faculty of Applied Science. Effective library support of design engineering comprises people, curriculum, collections and assessment. Moreover, effective support is seamless and fully embedded in the design students' learning over time. We discuss our experience to date and identify areas for future growth.
\end{abstract}

\section{Introduction}

Timing and location were the catalysts for our library re-design to support design engineering. In 1997 nine departmental science and engineering libraries were consolidated into the Engineering \& Science Library, where we serve all of the natural and applied science programs at Queen's University. Seven years later the Library created a position, the Integrated Learning Librarian, to work with the new Integrated Learning initiative in the Faculty of Applied Science. The position posting included this description: "the Integrated Learning Librarian, in collaboration with the Integrated Learning Centre, has the responsibility to identify, develop, promote, deliver and assess information services to applied science students and faculty members engaged in Integrated Learning programs and initiatives." One such central program is design engineering and, coincidentally, the new NSERC Chair in Design Engineering had just started at Queen's as well ... timing ...timing ...timing! This new librarian was welcomed to the Integrated Learning Centre Team with work space inside the newly constructed home for Integrated Learning in Beamish-Monro Hall ... location ... location ... location! [1]

\section{People}

Typical of many, if not most academic libraries we serve our community based on a departmental liaison model whereby each librarian is responsible for teaching, collections and research support with a number of academic departments. As well, we each have responsibilities across the spectrum of engineering and science departments (for example a Research Services and Undergraduate Services Librarian are part of our complement). What was new with the Integrated Learning Librarian was the mandate to work with design engineering as a crossdisciplinary endeavor and in partnership with the research and program development of the Design Engineering Chair. The Chair and Librarian started working together from the very beginning and as the Design program progresses so does our support for it. The Librarian and the Chair have worked intensely together developing course instruction and collection development (more on this below). The Librarian also enjoys close collaboration with the Engineering Education Chair and the Director of Program Development in the Faculty. Frequent contact with these individuals is augmented by participation in relevant committees, both formal and informal. There is no doubt that the simple fact of physical proximity has strengthened these relationships. It is most critical to our success that the faculty have signaled to the students through their attention that information skills are important engineering skills.

In Engineering \& Science all librarians work with design classes in our respective departmental liaison roles. Supporting senior year design classes predates the Library's involvement with Integrated Learning. Our participation was fragmented, however, as we served disparate departments. What we are just starting to do now is tie this together with a fundamental interdisciplinary understanding of design engineering. Currently, we maintain one 
course guide for each and every design class [2]. While we will continue to tailor course guides for specific needs we also realize there is a need for a Design Engineering Guide to act as the focal point for these discipline-specific ones. This is planned for the upcoming academic year. The Engineering \& Science librarians support each other in team teaching across our design courses and we have in our complement a patent specialist who creates learning tools used by all our design students.

We cannot overstate the importance of the librarians' enthusiasm for the design projects and their subject knowledge of information sources and management tools. Librarians become de facto team members for many groups with term-long communication and support on projects.

\section{Curriculum}

An early initiative of the Integrated Learning Librarian was the creation of a draft information literacy curriculum progressing through the four years of undergraduate engineering education. This draft plan was based on the ACRL Information Literacy Standards for Science and Technology [3]. Ultimately our goal is to ensure that upon graduation the newly minted engineers will be adroit at finding and managing information for problem solving and for maintaining state-of-the-art knowledge in their field of practice. In our plan we selected compulsory courses in each year for each discipline to embed information literacy units. The fourth-year design projects were natural candidates and we are active in seven such courses. In fact, these design classes were our first teaching foothold in several departments. Our experience shows that design projects are the most effective vehicles for students' learning of strategic and rigorous information retrieval and management. The students themselves seem to be most receptive to information literacy when they are engaged in creative design problems. This is intuitively sensible to us because the problems are open-ended with multiple solutions. Defining the problem and identifying what they need to know are critical first steps that design students tackle. In the future we will want to test this by comparing the efficacy of design engineering projects with that of engineering reports as alternative vehicles for information literacy.

How effective is information literacy instruction in design projects? Studies use two types of measurement tools for this. One can either measure the quality and quantity of the information resources used in the final design, or use the quality of design performance as the measurement tool. An example of the latter is a study from the Pennsylvania State University [4]. In the first year course Introduction to Engineering Design the students were taught in two sections by the same instructor; one received information literacy instruction while the other did not. Four sessions through the term comprised the information literacy unit. Design performance was measured by a combination of team quizzes, peer evaluations and final design reports. The student section that had participated in information literacy sessions did receive higher design performance evaluations that the other section. Another study of senior electrical engineering design students at the University of Washington evaluated the quantity and quality of information sources as the measure of the success of information literacy [5]. Half of the class received a single research session from the Engineering Librarian augmented by term-long communication while the other half of the class did not receive these. The bibliographies from the final reports showed that the first group did indeed use more high quality information sources. The authors also found a positive correlation between the inclusion of authoritative sources and the final report grade.

So, our experience tells us that design students are receptive to information literacy while studies at other engineering schools indicate that the students' learning is indeed enhanced by it. Is it sufficient then for the Library to wait until fourth-year design projects to meet the students "when they are ready?" Another observation we have made is that the students' self perception of research abilities tends to be inflated when they are in first year. The senior students are gratifying to work with because they are motivated, have developed engineering skills and are confident enough to recognize that they may not know some things. And yet, we find ourselves purposefully working with design engineering at all levels of the curriculum. There are a couple of reasons for this. The first and most important is our coordination with Integrated Learning and Program Development in Applied Science where first year is seen as the critical moment to set a strong foundation for the years ahead. The other compelling reason is given by the students themselves. They asked for it. Four years ago (the first year for the integrated learning librarian at Queen's) the integrated learning librarian met with the senior students in MECH460 Team Project: Conceive and Design. Assuming that 
the students had not had much library presence in their education to date, all the basics were covered in a one-hour presentation. At the end of the session 106 students responded to a brief survey of closed and open-ended questions: 


\begin{tabular}{|l|l|}
\hline Feel more confident after session & $77 \%$ \\
\hline $\begin{array}{l}\text { Knew some or none of this previous to } \\
\text { session }\end{array}$ & $87 \%$ \\
\hline $\begin{array}{l}\text { Interest in learning more about: } \\
\text { Patents }\end{array}$ & $43 \%$ \\
Standards & $36 \%$ \\
Business Information & $28 \%$ \\
Technical Articles & $28 \%$ \\
\hline
\end{tabular}

Table 1. Survey of senior Mechanical Design students [6]

The high number of students with little or no prior knowledge was revealing. One open-ended question asked what they had found most useful in the session. A significant number replied "everything" and many took the time to elaborate on what they wanted to learn more about. A frequent comment written and said to me after the class (and again when I met with senior Civil Engineering design students) was "Why didn't we learn this earlier?" Now they do.

For the last two years we have been working closely with the first-year students in the design project module in APSC100. Our involvement began two years ago with one-hour small-group sessions in the Library's electronic classroom. A model for information literacy module in this course was developed in 2007 which is based on ACRL standards as shown in figure 1 .

In winter term of 2008 our involvement had matured into three units: an introductory talk at the start of the course, a hands-on workshop when the projects are assigned, and consultations when the first drafts are submitted. The Integrated Learning Librarian is available for consultation with the students and their project tutors throughout the term.

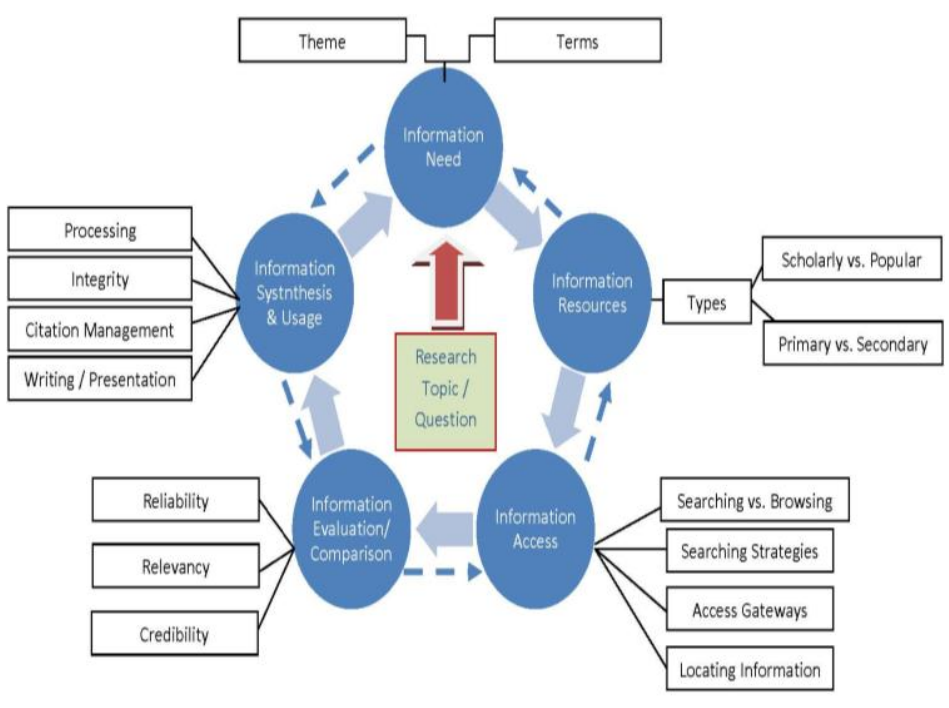

Figure 1. Information Skills for First Year Design Class

We currently work with some design students in years two and three in their departments. We work in partnership with the Design Chair on two multidisciplinary design stream courses APSC 381 and APSC480. The Integrated Learning librarian with the design course instructor are investigating the use of different tools that would engage students in the information seeking process during the projects that would include the use of collaborative websites and concept maps.

Although four years ago we selected the ACRL Information Literacy Standards for Science and Technology as our framework for an information literacy curriculum, we are exploring alternate models in the context of what we are learning about our students' learning and in response to curriculum planning in the Faculty. We hope to select and develop our framework this year.

\section{Collections}

Because design engineering places an emphasis on active learning, we need to have sufficient resources on-hand so the students can actually learn through use. We have a strong theoretical scholarly collection in Applied Science and, because we support undergraduate teaching, we have a strong book collection (recent purchases are electronic in all forms). To serve the needs of the design community 
we need as well to own or provide access to: technical reports, materials properties' databases, industry standards, government regulations, patents, market analysis, pricing / costing, legislation, geospatial data and statistics of all kinds. In the recent past we have placed emphasis on upgrading our standards collection. We conducted an inventory and added records for each standard to our Library catalogue. The collection is complete for some Standards Writing Organizations (e.g. IEEE) and selected for others (e.g. NFPA). We are in the process of adding electronic standards' libraries to our collection. Our most recent acquisition was the Canadian Standards Association Online Subscription Service providing access to all current and superseded CSA standards. As we work with student design teams we purchase individual standards on demand as they identify what they need.

Many design students are especially interested in patents. Most are available online and it is relatively easy to find "a" patent but it takes great skill to find "the" patent. We are fortunate to have a patent specialist in Engineering \& Science who creates guides and tutorials and gives workshops throughout the year to keep us all up to date.

The rate at which our book collection is converting to electronic format is increasing. Not only do our students prefer e-books, they especially appreciate those electronic reference collections that provide users with interactive tools such as those that let them select data and export them into Excel sheets or create customized graphs.

Design engineering is multidisciplinary stretching beyond the confines of an engineering collection. For those resources outside of our expertise we receive invaluable help from our librarian colleagues in business, law and GIS in particular. They advise on best approaches to finding information and will meet directly with the design groups.

\section{Assessment}

At a curriculum level we need a tool that will measure the impact of information literacy on student learning throughout their four years of undergraduate education while controlling for external variables. To our knowledge there is no such tool developed yet. However, we recognize that we need continual assessment of student learning so we can measure and craft our work with the students within their individual courses. We use a variety of assessment tools. In APSC100 a sub-group of students is given a pre- and post-test of their information literacy skills through a brief quiz that asks them to identify what information they would need and where they would find it for a design problem. In the same course they complete a course assessment which includes questions about the usefulness of the information sessions. The Integrated Learning Librarian also surveys the students as he works with them in class. Several of us use Survey Monkey at the end of sessions for immediate feedback and we also rely on reviewing the students' references when they submit final reports.

Assessment remains our biggest challenge and an area of focus for us working with engineering faculty and other library colleagues.

\section{Conclusion}

Collaboration with Design Engineering has helped us to re-design our library. The significant changes to date are: focusing our engineering information research instruction on design with interdisciplinary design as the hub; inclusion of information management in instruction sessions; building the standards collection; creating patent teaching objects; moving librarians from the library to the engineering departments; and developing a curriculum with a strong first year foundation.

\section{References}

[1] For an overview of the Integrated Learning Centre and initiatives see: http://appsci.queensu.ca/ilc/

[2] To view our current course guides see: http://library.queensu.ca/webeng/courseguides.htm

[3] American College and Research Libraries, Science and Technology Section (2004). Information Literacy Standards for Science and Technology: http://www.ala.org/ala/acrl/acrlstandards/infolitscitech.htm.

[4] G. Okudan and B. Osif, "Effect of Guided Research Experience on Product Design Performance", Journal of Engineering Education, vol. 94, iss. 2, pp. 255-260.

[5] B. Otis and Linda Whang, "Effect of library instruction on undergraduate electrical engineering design projects", Proceedings of the 2007 American Society for Engineering Education Annual Conference and Exposition, ASEE, Honolulu, June 2007.

[6] Survey was completed by 106 students at the end of a one hour session on information research for their senior 
design projects in the fall of 2004. Contact the authors for the full survey and results. 